\title{
A distinct physiological role of MutY in mutation prevention in mycobacteria
}

\author{
Krishna Kurthkoti, ${ }^{1}$ Thiruneelakantan Srinath, ${ }^{1}$ Pradeep Kumar, ${ }^{1}$ \\ Vidyasagar S. Malshetty, ${ }^{1}$ Pau Biak Sang, ${ }^{1}$ Ruchi Jain, ${ }^{1}$ \\ Ramanathapuram Manjunath ${ }^{2}$ and Umesh Varshney ${ }^{1}$ \\ ${ }^{1}$ Department of Microbiology and Cell Biology, Indian Institute of Science, Bangalore, 560012, India \\ ${ }^{2}$ Department of Biochemistry, Indian Institute of Science, Bangalore, 560012, India
}

Correspondence

Umesh Varshney

varshney@mcbl.iisc.ernet.in

Received 10 August 2009

Revised 18 September 2009

Accepted 21 September 2009

\begin{abstract}
Oxidative damage to DNA results in the occurrence of 7,8-dihydro-8-oxoguanine (8-oxoG) in the genome. In eubacteria, repair of such damage is initiated by two major base-excision repair enzymes, MutM and MutY. We generated a MutY-deficient strain of Mycobacterium smegmatis to investigate the role of this enzyme in DNA repair. The MutY deficiency in $M$. smegmatis did not result in either a noteworthy susceptibility to oxidative stress or an increase in the mutation rate. However, rifampicin-resistant isolates of the MutY-deficient strain showed distinct mutations in the rifampicin-resistance-determining region of $r p o B$. Besides the expected $C$ to $A$ (or $G$ to $T$ ) mutations, an increase in $\mathrm{A}$ to $\mathrm{C}$ (or $\mathrm{T}$ to $\mathrm{G}$ ) mutations was also observed. Biochemical characterization of mycobacterial MutY (M. smegmatis and M. tuberculosis) revealed an expected excision of A opposite 8-oxoG in DNA. Additionally, excision of $G$ and $T$ opposite 8-oxoG was detected. MutY formed complexes with DNA containing 8-oxoG : A, 8-oxoG: $G$ or 8-oxoG :T but not 8-oxoG:C pairs. Primer extension reactions in cell-free extracts of $M$. smegmatis suggested error-prone incorporation of nucleotides into the DNA. Based on these observations, we discuss the physiological role of MutY in specific mutation prevention in mycobacteria.
\end{abstract}

\section{INTRODUCTION}

Reactive oxygen species produced during cellular metabolism or encountered as environmental pollutants inflict severe damage on the integrity of DNA. Of the four bases in DNA, guanine is highly susceptible to oxidative stress, resulting in the formation of 7,8-dihydro-8-oxoguanine (8oxoG) or its derivatives (Fraga et al., 1990; Farr \& Kogoma, 1991; Delaney et al., 2007; David et al., 2007). The presence of oxidized $\mathrm{G}$ in DNA is mutagenic because of its pairing with A or G. Eubacteria possess an elaborate 8-oxoG (GO) repair system consisting of Fpg (MutM), MutY and MutT enzymes to deal with such threats to genomic integrity (Michaels \& Miller, 1992; Tajiri et al., 1995; Fowler et al., 2003; Bruner et al., 2000). Fpg is known to excise 8-oxoG paired with $\mathrm{C}$ or $\mathrm{T}$ and initiate the base-excision repair pathway. MutY is an atypical DNA glycosylase whose predominant activity removes A or G incorporated against 8-oxoG during replication (Au et al., 1989; Lu \& Chang, 1988; Tsai-Wu et al., 1992). Such MutY activity increases the chances of incorporating the correct base (C) against 8-

Abbreviations: EMSA, electrophoretic mobility shift assay; GO or 8oxoG, 7,8-dihydro-8-oxoguanine; RRDR, rifampicin resistance determining region.

Supplementary material is available with the online version of this paper.
oxoG, as well as the probability of further repair of the lesion (8-oxoG) by Fpg. Thus, the action of MutY prior to the second round of DNA replication provides an efficient mechanism to decrease fixation of $A$ or $G$ in place of $C$ in the genome, and prevents $\mathrm{C}$ to $\mathrm{A}$ (or $\mathrm{G}$ to $\mathrm{T}$ ) and to a lesser extent $\mathrm{C}$ to $\mathrm{G}$ ( $\mathrm{G}$ to $\mathrm{C}$ ) mutations. In addition, Escherichia coli MutY has been reported to possess a weak activity of excising A from C: A mismatch (Tsai-Wu et al., 1992). The third enzyme of the GO repair pathway, MutT, cleaves 8oxo-dGTP (to 8-oxo-dGMP) from the nucleotide pool to minimize its direct incorporation into DNA (Michaels \& Miller, 1992; Mo et al., 1992).

The capacity to repair 8-oxoG damage is considered to be crucial in $\mathrm{G}+\mathrm{C}$-rich bacteria such as Mycobacterium tuberculosis, an important human pathogen which is exposed to reactive oxygen species within the host macrophages. Studies on the DNA repair mechanisms of this group of organisms are in early stages but they are believed to be important during dormancy or the active multiplication phase of the pathogen. However, the genome sequence of $M$. tuberculosis revealed that this organism lacks the mismatch repair enzymes (Cole et al., 1998; Mizrahi \& Andersen, 1998). Thus, the base-excision repair and nucleotide-excision repair pathways must contribute significantly to the maintenance of genomic integrity in these bacteria. 
We have been using Mycobacterium smegmatis as a model to carry out genetic analysis of various DNA repair enzymes in mycobacteria (Venkatesh et al., 2003; Jain et al., 2007; Kurthkoti et al., 2008). It had been observed that in mycobacteria, C to A (or $\mathrm{G}$ to $\mathrm{T}$ ) mutations occurred minimally (Boshoff et al., 2003). Further, unlike an E. coli $f p g$ strain, an M. smegmatis $f p g$ strain showed no detectable increase in $\mathrm{C}$ to $\mathrm{A}$ mutations. However, the strain suffered a significant increase in A to $G$ (or $T$ to $C$ ) and $\mathrm{C}$ to $\mathrm{G}$ (or G to C) mutations (Jain et al., 2007).

Recently, it has been reported that in Pseudomonas aeruginosa, another $\mathrm{G}+\mathrm{C}$ rich organism, loss of mut $Y$ had a greater impact on spontaneous mutation rate than loss of fpg (Sanders et al., 2009). A distinct impact of Fpg deficiency in M. smegmatis (Jain et al., 2007) encouraged us to further our knowledge of the physiological significance of the GO repair pathway in mycobacteria. In this study, we generated a MutY-deficient strain of M. smegmatis and assessed the role of MutY in the GO repair pathway. We then biochemically characterized $M$. tuberculosis MutY, which shows high similarity with the $M$. smegmatis counterpart, to understand the mechanism underlying the mutation spectrum in the MutY-deficient strain.

\section{METHODS}

DNA oligomers, plasmids, strains, media and growth conditions. A list of DNA oligomers and plasmids is provided in Supplementary Table S1 (available with the online version of this paper); the strains used are summarized in Table 1. Media components were from Difco. M. smegmatis $\mathrm{mc}^{2} 155$ (Snapper et al., 1990) was grown in Luria-Bertani (LB) containing $0.2 \%(\mathrm{v} / \mathrm{v})$ Tween 80 (LBT), or in Middlebrook $7 \mathrm{H} 9$ containing $0.2 \%(\mathrm{v} / \mathrm{v})$ glycerol and $0.2 \%$ Tween 80 . LBT agar contained $1.5 \%(\mathrm{w} / \mathrm{v})$ agar. Genetically engineered strains of $M$. smegmatis were selected on Middlebrook $7 \mathrm{H} 10$ agar containing $0.5 \%$ glycerol, $0.05 \%$ Tween 80 and $10 \%(\mathrm{w} / \mathrm{v})$ sucrose. Media were supplemented with hygromycin, gentamicin and kanamycin at $50 \mu \mathrm{g} \mathrm{ml}^{-1}, 5 \mu \mathrm{g} \mathrm{ml}^{-1}$ and $50 \mu \mathrm{g} \mathrm{ml}^{-1}$, respectively, as needed.

Generation of mutY disruption allele, screening and Southern blot analysis. $M$. smegmatis mutY (Msm-mutY, MSMEG_6083) was identified by its homology with the M. tuberculosis mutY (Rv3589; Cole et al., 1998) from the M. smegmatis sequence retrieved from The
Institute of Genomics Research (http://www.tigr.org); it was disrupted in $M$. smegmatis $\mathrm{mc}^{2} 155$ by a $\mathrm{Kan}^{\mathrm{R}}$ marker to generate the mutY:: kan strain (for details see supplementary online material).

MutY activity assays. Double-stranded DNA oligomers were generated by annealing $5^{\prime}{ }^{32} \mathrm{P}$ end-labelled Comp-G, Comp-A, Comp-T, and Comp-C oligomers with the 8-oxoG oligomer (Supplementary Table S1) and used for MutY activity assays essentially as described by Jain et al. (2007); see Supplementary online material for details.

Generation of an M. smegmatis mutY strain complemented with ectopically expressed mutY. The Msm-mutY gene was amplified from M. smegmatis using a forward (Msm-mutYUP-Fp) and a reverse (Msm-mutYDN2-Rp) primer as a $\sim 1.6 \mathrm{~kb}$ amplicon, and subcloned into pMV361to generate pMV-Msm-mutY, wherein the expression of mutY would be driven by its own promoter (see Supplementary online material for details). pMV-Msm-mut $Y$ was introduced into the $M$. smegmatis mut $Y$ : : kan strain by electroporation and the complemented strain was named mutY (L5att::mutY). A control strain, mutY (L5att:: vector), referred to as the mutY strain, was generated by transformation of the empty vector, pMV361, into the $m u t Y:$ : kan strain (other strain designations are summarized in Table 1).

Effect of hydrogen peroxide on bacterial growth. Growth of $M$. smegmatis strains was monitored in a Bioscreen $\mathrm{C}$ kinetic growth reader (OY Growth) at $37{ }^{\circ} \mathrm{C}$ with constant shaking as described previously (Kurthkoti et al., 2008).

Survival of $\boldsymbol{M}$. smegmatis strains in RAW 264.7 cells. Murine macrophage cell line RAW 264.7 was maintained in DMEM (Sigma) with glucose $\left(4.5 \mathrm{mg} \mathrm{ml}^{-1}\right)$ and $10 \%$ fetal calf serum (Gibco). Cells were seeded in 24-well tissue culture plates $\left(0.2 \times 10^{6}\right.$ per well $)$ in $1 \mathrm{ml}$ complete medium and allowed to adhere for $14 \mathrm{~h}$. Bacteria were grown in LBT to an $\mathrm{OD}_{600}$ of $\sim 0.4$ from a $48 \mathrm{~h}$ old pre-culture. The bacterial cultures $(0.15 \mathrm{ml})$ were mixed with $1.35 \mathrm{ml}$ tissue culture medium at an m.o.i. of $\sim 10$. The infections were done in triplicate in $0.2 \mathrm{ml}$ at $37{ }^{\circ} \mathrm{C}$ in $5 \% \mathrm{CO}_{2}$ for $5 \mathrm{~h}$, and cells were washed twice with PBS and treated with gentamicin $\left(100 \mu \mathrm{g} \mathrm{ml}^{-1}\right)$ for $1 \mathrm{~h} 30 \mathrm{~min}$ to kill the extracellular bacteria. Cells were washed again with PBS and incubated in $2 \mathrm{ml}$ DMEM containing $20 \mu \mathrm{g}$ gentamicin $\mathrm{ml}^{-1}(0 \mathrm{~h}$ time point). Cells were lysed at $0,24,48$ and $72 \mathrm{~h}$ in PBS containing $0.5 \%$ Triton X-100 (Sigma) and the total viable counts of the recovered bacteria were determined by dilution plating on LBT agar. Counts from triplicate samples were analysed and plotted.

Determination of mutation rates. Mutation rates were determined as described before (David, 1970; Kurthkoti et al., 2008).

Table 1. M. smegmatis strains

\begin{tabular}{|c|c|c|}
\hline Strain & Relevant details & Reference \\
\hline$m c^{2} 155$ & A high-efficiency transformation strain of $M$. smegmatis & Snapper et al. (1990) \\
\hline WT & $\begin{array}{l}\mathrm{mc}^{2} 155 \text { harbouring an integrative vector, pDK20 }\left(\mathrm{Kan}^{\mathrm{R}}\right) \text { at the L5 attachment } \\
(\mathrm{att}) \text { site of the chromosome }\end{array}$ & Venkatesh et al. (2003) \\
\hline mutY: :kan & $\mathrm{mc}^{2} 155$ wherein $m u t Y$ gene has been disrupted with a kan cassette & This study \\
\hline mutY & $\begin{array}{l}\text { mut } Y: \text { kan strain harbouring the integrative vector pMV361 }\left(\mathrm{Hyg}^{\mathrm{R}}\right) \text { at the L5 } \\
\text { attachment (att) site of the chromosome }\end{array}$ & \\
\hline mut $Y$ (L5att: : mut Y) & $\begin{array}{l}\text { mut } Y \text { strain harbouring the integrative plasmid pMV-Msm-mut } Y \text { at the L5 att } \\
\text { site of the chromosome }\end{array}$ & \\
\hline fpg:: hyg & $\mathrm{mc}^{2} 155$ wherein $f g p$ gene has been disrupted with a $h y g$ marker & Jain et al. (2007) \\
\hline fpg & $f p g:: h y g$ strain harbouring a replicative plasmid, pTKmx $\left(\operatorname{Kan}^{\mathrm{R}}\right)$ & Jain et al. (2007) \\
\hline
\end{tabular}


Analysis of mutation spectrum. $M$. smegmatis cultures were plated on LBT agar containing rifampicin $\left(50 \mu \mathrm{g} \mathrm{m}^{-1}\right)$ and incubated at $37{ }^{\circ} \mathrm{C}$ for $96 \mathrm{~h}$. The isolated colonies were suspended in $20 \mu \mathrm{l}$ water, incubated at $90{ }^{\circ} \mathrm{C}$ for $5 \mathrm{~min}$, spun at 13000 r.p.m. for $5 \mathrm{~min}$ in a table-top centrifuge and the supernatant was used as template to PCR amplify the rifampicin-resistance determining region (RRDR) with Taq DNA polymerase and the 306-rpoB-Fp and 306-rpoB-Rp primers (Jain et al., 2007). The PCR products were eluted from agarose gel and sequenced using the Msm-rpoB-seq-Fp primer (Macrogen).

Cloning of MtuMutY into pET11d and purification of MtuMutY. The MtuMutY (Rv3589) ORF was amplified by PCR from $M$. tuberculosis DNA using primers Mtu-mutY-Fp (beginning with the second codon in the ORF) and Mtu-mutY-Rp (which anneals $\sim 0.15 \mathrm{~kb}$ downstream of the termination codon) and Dynazyme EXT polymerase. The reaction was heated at $94{ }^{\circ} \mathrm{C}$ for $4 \mathrm{~min}$ followed by 30 cycles of incubation at $94{ }^{\circ} \mathrm{C}$ for $1 \mathrm{~min}, 50{ }^{\circ} \mathrm{C}$ for $45 \mathrm{~s}$ and $70{ }^{\circ} \mathrm{C}$ for $1 \mathrm{~min}$. The PCR product was cloned into pGEM-T Easy vector. The sequence of the insert was confirmed by DNA sequencing, released by EcoRI digestion and subcloned into pTrc99c linearized with EcoRI. After confirming the correct orientation, the mutY fragment was released by $\mathrm{NcoI}$ and $\mathrm{BamHI}$ and mobilized into similarly digested pET11d to give pETMtuMutY. During these manipulations, a Gly-Asn-Ser-Ile sequence was added between the initiator methionine and the second amino acid of the MutY sequence. Details of the purification of MtuMutY using the pETMtuMutY expression construct are provided in the supplementary online material.

Analysis of complex formation of MtuMutY with 8-oxoGcontaining DNA. Electrophoretic mobility shift assays (EMSAs) were carried out as described previously (Srinath et al., 2007). Briefly, MtuMutY (200 ng) was incubated with 10000 c.p.m. of radiolabelled ssDNA or dsDNA $(\sim 0.1 \mathrm{pmol})$ on ice for $15 \mathrm{~min}$ in EMSA buffer [20 mM Tris/HCl (pH 8.0), $50 \mathrm{mM} \mathrm{NaCl}, 5 \%$ (v/v) glycerol, $1 \mathrm{mM}$

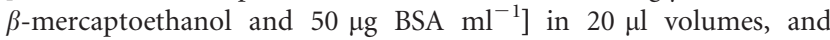
resolved on $10 \%$ native polyacrylamide $(19: 1)$ gels of $0.75 \mathrm{~mm}$ thickness and $160 \mathrm{~mm}$ length at $150 \mathrm{~V}$ in cold room $\left(8^{\circ} \mathrm{C}\right)$ using $0.5 \times$ TBE. Bands corresponding to the complex and the free DNA were identified by BioImage Analyser.

Incorporation of G and 8-oxoG into DNA by M. smegmatis cellfree extracts. Cell-free extracts from $M$. smegmatis $\mathrm{mc}^{2} 155$ were prepared as described previously (Jain et al., 2007) and used in the primer extension assays. The substrates for primer extension were prepared by annealing of a $5^{\prime}{ }^{32} \mathrm{P}$-end labelled Extension-oligo (Supplementary Table S1) as primer with Comp-G, Comp-A, Comp$\mathrm{T}$ and Comp-C oligomers (Table 1). The substrates allow for extension of the primer by incorporation of the nucleotide(s) against $\mathrm{G}, \mathrm{A}, \mathrm{T}$ or $\mathrm{C}$ in the template. The reaction $(10 \mu \mathrm{l})$ contained $5 \mu \mathrm{g}$ cellfree extract, 12000 c.p.m. of the primer-extension substrate, 5 pmol FpKRS, 50 or $100 \mu \mathrm{M}$ 8-oxo-dGTP or dGTP in $10 \mathrm{mM}$ Tris/HCl (pH 7.9), $10 \mathrm{mM} \mathrm{MgCl}_{2}, 50 \mathrm{mM} \mathrm{NaCl}$ and $1 \mathrm{mM}$ DTT. The reactions were incubated at $37^{\circ} \mathrm{C}$ for $5 \mathrm{~min}$, stopped with $10 \mu \mathrm{l}$ $80 \%$ formamide dye, heated at $90{ }^{\circ} \mathrm{C}$ for $5 \mathrm{~min}$, then analysed on $8 \mathrm{M}$ urea $/ 15 \%$ polyacrylamide gel and visualized by BioImage Analyser.

\section{RESULTS}

\section{Disruption of mutY in M. smegmatis}

M. smegmatis has served as a faithful model in genetic analyses of the fundamental processes of DNA repair in mycobacteria. Hence, to understand the physiological significance of MutY in this important group of bacteria, we identified $M$. smegmatis mutY (MSMEG_6083) by its homology to M. tuberculosis mut $Y$ (Rv3589). Comparison of the genomic contexts (Fig. 1a) also suggested that MSMEG_6083 and Rv3589 are orthologues. To generate a mut $Y$ null allele of $M$. smegmatis, we disrupted a cloned copy of M. smegmatis mut $Y$ by replacing $\sim 0.1 \mathrm{~kb}$ of its ORF with a kan cassette and introduced the generated construct, pPR-Msm-mutY:: kan, into M. smegmatis to effect allelic exchange of the chromosomal copy with the disrupted allele (Pelicic et al., 1997). PCR-based screening showed single amplicons of $\sim 1.3$ and $2.5 \mathrm{~kb}$, respectively, from the parent M. smegmatis $\mathrm{mc}^{2} 155$ (defined as wild-type) and the derived mutant strains (Fig. 1c, lanes 1 and 2). This observation agreed with the expected pattern (Fig. 1b) and indicated a successful exchange of the wild-type $m u t Y$ allele with the disrupted (mutY::kan) allele. Genomic blot analysis also revealed bands of the expected sizes of $\sim 4.4$ and $\sim 5.6 \mathrm{~kb}$ upon EcoRV digestion of the genomic DNA from the two strains (Fig. 1d, lanes 1 and 2).

To ensure that the disruption of the chromosomal copy of mut $Y$ resulted in the deficiency of MutY activity, we used cell-free extracts from the mutY::kan strain and its derivative harbouring pMV-Msm-mutY at the L5att site [strain mutY (L5att:: mutY)] for the activity assays. A duplex containing a ${ }^{32} \mathrm{P} \quad 5^{\prime}$-labelled oligomer (Comp-A oligo, Table S1) with an A at position 15, opposite 8-oxoG in the complementary strand, was used as substrate, $\mathrm{S}$ (Fig. 1e). In the assay, excision of the A residue from the Comp-A oligo followed by the cleavage of the backbone results in two fragments, one of which $\left({ }^{32} \mathrm{P}\right.$-labelled) is detected as a faster-migrating product $(\mathrm{P})$ band upon gel electrophoresis. As seen in Fig. 1(e), the cell-free extracts prepared from the parent strain (wild-type) resulted in processing of the 30-mer duplex DNA (lane 3), as in the control reaction with the M. tuberculosis MutY (MtuMutY, lane 2). This activity was largely missing from the extracts of the MutY-deficient strain (mutY::kan, lane 4). However, the activity was restored in the extracts prepared from the complemented strain (lane 5) harbouring an intact copy of mut Y at the L5att site [mutY (L5att: : mutY)]. These experiments show that disruption of mut $Y$ with the kan cassette results in a deficiency of MutY activity, and the deficiency is rescued by an ectopically inserted copy of the mut $Y$ gene.

\section{Determinaion of mutation rates}

The effect of loss of mutY on DNA repair was investigated by determining mutation rates by spontaneous appearance of rifampicin resistance $\left(\mathrm{Rif}^{\mathrm{R}}\right)$. As shown in Table 2, the deficiency of MutY did not result in a significant change in the mutation rate of the mut $Y:$ kan strain over that of the parent strain $(\sim 1.3$-fold $)$. However, consistent with our earlier report (Kurthkoti et al., 2008), deficiency of Fpg (strain $f p g:: h y g$ ) led to a moderate ( 3-fold) increase in the mutation rate. 
(a)

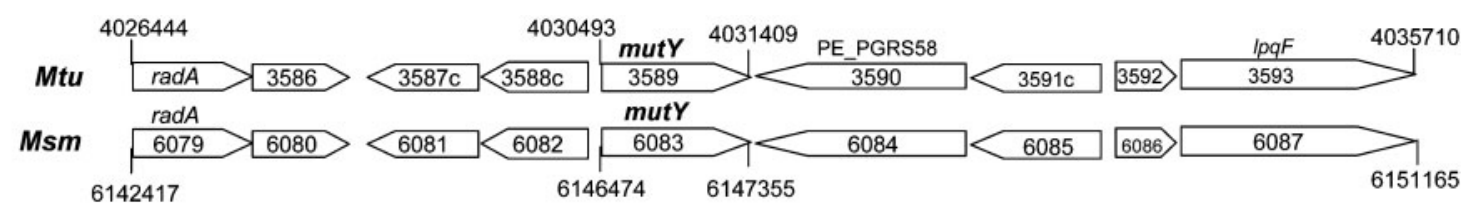

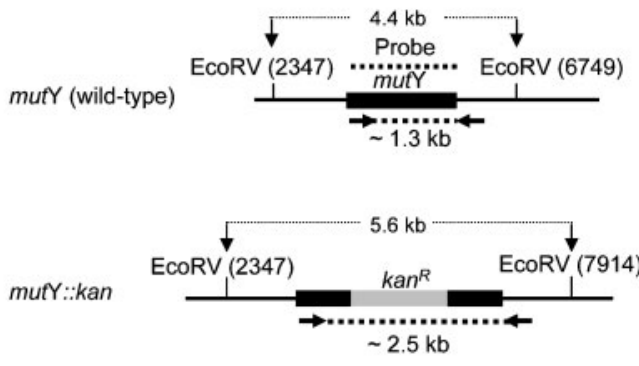

(b)

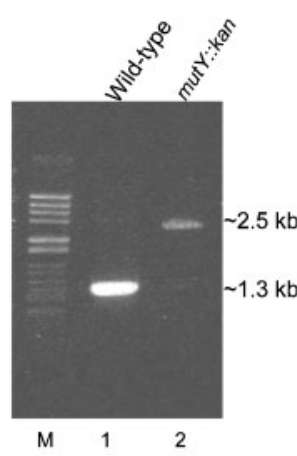

(c)

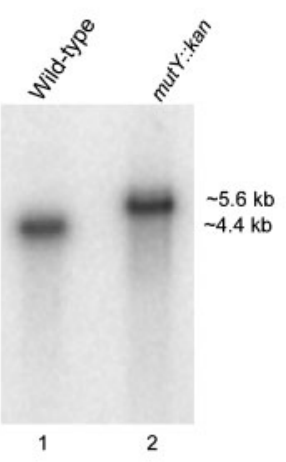

(d)

(e)

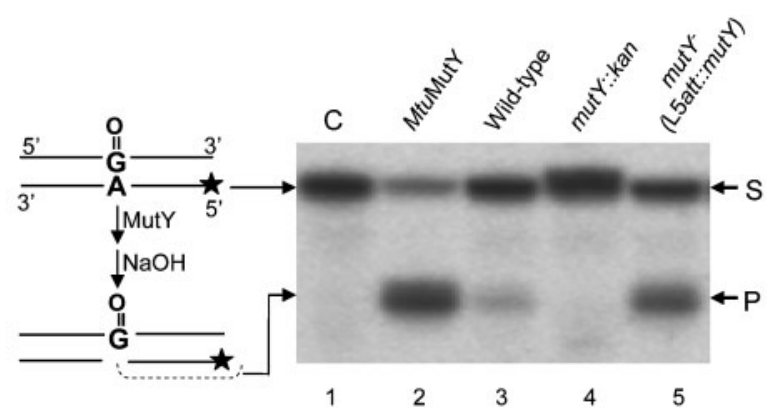

Fig. 1. Generation and characterization of the M. smegmatis mutY::kan strain. (a) Schematic representation (not to scale) of the genomic context of mut $Y$ in M. smegmatis (Msm) between positions 6142417 and 6151165 , and its comparison with that from the M. tuberculosis (Mtu) genome between positions 4026444 and 4035710. Annotations for M. smegmatis genome (MSMEG numbers) are as follows: 6079, DNA repair protein RadA; 6080 and 6081, conserved hypothetical proteins; 6082 , carbonic anhydrase (homologous to Rv3588c); 6083, probable adenine glycosylase (MutY); 6084, AraC-family transcriptional regulator; 6085 , hydrolase; 6086, antibiotic biosynthesis monooxygenase domain protein; $6087, \beta$-lactamase. Annotations for M. tuberculosis (Rv numbers) are as follows: RadA, DNA repair protein; 3586, conserved hypothetical protein; 3587c, probable conserved membrane protein; 3588c, carbonic anhydrase; 3589, probable adenine DNA glycosylase (MutY); 3590, PE_PGRS family protein; 3591c, possible hydrolase; 3592, conserved hypothetical protein (gene TB11.2); and 3593, probable conserved lipoprotein, LpqF. (b) Schematic representation of the expected sizes of the amplicons in PCR, and fragments in genomic blots from the wild-type (upper panel) and the disrupted mutY: :kan (lower panel) loci. The location of the mut $Y$ gene-specific probe used in the genomic blot (panel c) is indicated by a dotted line above the mut $Y$ gene in the upper panel. (c) Agarose gel electrophoresis of the PCR amplicons from the wild-type (lane 1) and the mutY null strains (mutY:: kan, lane 2). Lane M shows $\lambda$ DNA Hindll/Hindlll size markers. (d) Genomic blots of wild-type and mutY:: kan M. smegmatis strains. Sizes of DNA bands are indicated. (e) MutY activity assays with cell-free extracts $(25 \mu \mathrm{g})$ prepared from various strains (as indicated) or purified $M$. tuberculosis MutY (lane 2). The Comp-A strand was $5^{\prime}{ }^{32} \mathrm{P}$ labelled, and 20000 c.p.m. ( 0.1 pmol) of the duplex DNA containing 8-oxoG : A pairs were used. The reaction contents were analysed on $8 \mathrm{M}$ urea-15\% polyacrylamide gel. Lane 1, is a substrate alone negative control (c). The bands corresponding to product and substrate are indicated as $\mathrm{P}$ and $\mathrm{S}$, respectively.

\section{Analysis of mutation spectrum}

The effect of MutY deficiency on the mutation spectrum was determined by DNA sequence analysis of the RRDR from $\operatorname{Rif}^{\mathrm{R}}$ isolates of the mutY: : kan strain and comparison with that of the parent strain (Table 3, Supplementary Fig. S1). It was observed that loss of mutY resulted in an increase in $\mathrm{C}$ to $\mathrm{A}$ ( $\mathrm{G}$ to $\mathrm{T}$ ) mutations over the wild-type (to $15 \%$ over an undetectable value). Furthermore, an increase in the $\mathrm{A}$ to $\mathrm{C}$ (or $\mathrm{T}$ to $\mathrm{G}$ ) mutations from $2 \%$ to $28 \%$, and an increase in $\mathrm{A}$ to $\mathrm{G}$ (or $\mathrm{T}$ to $\mathrm{C}$ ) mutations from $34 \%$ to $48 \%$ also occurred. These increases are compensated for by a decrease in the frequency of other mutations. The contribution of the $\mathrm{C}$ to $\mathrm{T}$ (or $\mathrm{G}$ to A) mutations, which accounted for $52 \%$ of the mutations in the parent background, decreased to $\sim 4 \%$ in the mutY::kan strain 
Table 2. Effect of deficiency in DNA repair enzymes on mutation rate

\begin{tabular}{|lccc|}
\hline Strain & $\begin{array}{c}\mathbf{1 0}^{-\mathbf{9}} \times \text { Total no. of } \\
\text { viable bacteria plated }\end{array}$ & $\begin{array}{c}\mathbf{1 0}^{\mathbf{1 0}} \times \text { Mutation } \\
\text { rate } \dagger\end{array}$ & $\begin{array}{c}\text { Fold } \\
\text { increase }\end{array}$ \\
\hline WT & $7.3 \pm 0.63$ & 2.1 & 1.0 \\
mutY:: kan & $6.3 \pm 1.6$ & 2.82 & 1.34 \\
fpg: : hyg & $7.9 \pm 1.8$ & 6.46 & 3.07 \\
\hline
\end{tabular}

${ }^{*}$ Mean \pm SD of the total viable counts (determined by dilution plating of an aliquot) of bacteria in the 6 day cultures used to plate on rifampicin plates.

$\dagger$ Mutation rates were calculated according to David (1970) using the equation $a=2 \times \ln 2\left[\left(M_{\mathrm{t}} / N_{\mathrm{t}}\right)-\left(M_{0} / N_{0}\right)\right] / n \quad[a$, mutation rate; $n$, number of generations; $M_{\mathrm{t}}$, number of $\mathrm{Rif}^{\mathrm{R}}$ colonies obtained from the 6 day culture (Methods); $N_{\mathrm{t}}$, number of bacteria in the 6 day culture; $M_{0}$, number of Rif ${ }^{\mathrm{R}}$ colonies in the starter diluted culture used to make 6 day culture; $N_{0}$, number of bacteria in the starter culture used to make the 6 day culture]. The value of $n$ was calculated as $\left(\log _{10} N_{\mathrm{t}}-\log _{10} N_{0}\right) / 0.301$. As the value of $M_{0}$ was 0 , the simplified equation $\mathrm{a}=2 \times \ln 2\left(M_{\mathrm{t}} / N_{\mathrm{t}}\right) / n$ was used to calculate mutation rates. Mutation rates were calculated for all 12 replicates of the 6 day cultures, and the mean mutation rates shown were calculated from ten replicates, eliminating the two with the highest and the lowest rates.

(see Discussion). High occurrence of $\mathrm{C}$ to $\mathrm{T}$ mutations in the parent strain in our studies as well as those reported earlier (Boshoff et al., 2003) suggests that in mycobacteria, with a $\mathrm{G}+\mathrm{C}$-rich genome, there is a significant level of background cytosine deamination, and when the bacteria are challenged with Rif, frequently it is the $\mathrm{C}$ to $\mathrm{T}$ mutations that are selected to confer Rif ${ }^{\mathrm{R}}$.

Table 3. Spectrum of mutations in the RRDR locus of rifampicin-resistant isolates of $M$. smegmatis (wild-type) and M. smegmatis mutY:: kan

Information on the positions of the changes is summarized in Supplementary Fig. S1.

\begin{tabular}{|lcc|}
\hline \multirow{2}{*}{ Mutations detected } & \multicolumn{2}{c|}{ Strain } \\
\cline { 2 - 3 } & WT $^{*}$ & mutY: $:$ kan $\dagger$ \\
\hline $\mathrm{C} \rightarrow \mathrm{T} / \mathrm{G} \rightarrow \mathrm{A}$ & $52 \%(30 / 58)$ & $4 \%(2 / 46)$ \\
$\mathrm{C} \rightarrow \mathrm{G} / \mathrm{G} \rightarrow \mathrm{C}$ & $7 \%(4 / 58)$ & $4 \%(2 / 46)$ \\
$\mathrm{C} \rightarrow \mathrm{A} / \mathrm{G} \rightarrow \mathrm{T}$ & None & $15 \%(7 / 46)$ \\
$\mathrm{A} \rightarrow \mathrm{G} / \mathrm{T} \rightarrow \mathrm{C}$ & $34 \%(20 / 58)$ & $48 \%(22 / 46)$ \\
$\mathrm{A} \rightarrow \mathrm{C} / \mathrm{T} \rightarrow \mathrm{G}$ & $2 \%(1 / 58)$ & $28 \%(13 / 46)$ \\
$\mathrm{A} \rightarrow \mathrm{T} / \mathrm{T} \rightarrow \mathrm{A}$ & $5 \%(3 / 58)$ & None \\
$\mathrm{No}$ mutations in RRDR $\ddagger$ & $21 / 79$ & $2 / 48$ \\
& & \\
\hline
\end{tabular}

${ }^{\star}$ A total of 79 samples were sequenced, of which 58 samples showed mutations in RRDR.

$\dagger$ A total of 48 samples were sequenced, of which 46 showed mutations in RRDR.

$\ddagger$ Mutations elsewhere resulted in resistance to rifampicin.

\section{Effect of hydrogen peroxide on mutY strain}

We have shown previously that Fpg deficiency in $M$. smegmatis resulted in susceptibility of the mutant (fpg::hyg) to $\mathrm{H}_{2} \mathrm{O}_{2}$. Hence, it was of interest to analyse the effect of $\mathrm{H}_{2} \mathrm{O}_{2}$ on the growth of M. smegmatis deficient in MutY and compare it with the growth of the parent $M$. smegmatis, and the strain deficient in Fpg (MutM). All the strains showed comparable growth in the absence of peroxide (Fig. 2a, panel i), indicating that the loss of DNA repair enzymes (Fpg and MutY) did not affect the general growth kinetics of the bacteria. However, with the addition of $\mathrm{H}_{2} \mathrm{O}_{2}$ in the growth medium (Fig. 2a, panel iii), while the growth of the $f p g$ strain was seen to decrease, the growth profiles of the mutY and the mutY (L5att:: mutY) strains were similar to that of the parent strain.

\section{Cell infection assays}

M. smegmatis, a saprophytic organism, does not survive for prolonged periods in an intracellular environment. However, cell infection assays have been used to assess the effect of various mutations on the intracellular survival of the bacterium (Lagier et al., 1998, Dheenadhayalan et al., 2006). Also, it is known that macrophage cell lines inflict oxidative-stress-related damage on the DNA of the intracellular bacteria (Schlosser-Silverman et al., 2000). Hence, we studied the consequence of MutY deficiency on the survival of the M. smegmatis strains in RAW 264.7 macrophage cells of mouse origin (Fig. 2b). As expected, all the strains were gradually cleared from the RAW 264.7 cells. However, the $f p g$ strain was cleared relatively faster than the parent or the mut $Y$ strains (see the 48 and $72 \mathrm{~h}$ time points). Although, when compared with the parent strain, there is a detectable impact of MutY deficiency on the survival of the mut $Y$ strain, this is minor ( 2-fold, see 48 and $72 \mathrm{~h}$ time points). When the mutY strain was complemented with a copy of mutY gene in its L5 locus, the survival of the complemented strain was rescued. These results indicate that MutY contributes to counteracting the intracellular stress, although under the conditions used, its contribution is less than that of Fpg.

\section{Substrate specificity of mycobacterial MutY}

We have previously analysed the base-excision activity of mycobacterial MutY using substrates containing different nucleotides against 8-oxoG and $M$. smegmatis cell-free extracts, and shown that it possessed a predominant activity of processing A against 8-oxoG and a minor activity of processing G against 8-oxoG (Jain et al., 2007). In this study, use of the $M$. smegmatis mut $Y$ cell-free extract as a negative control allowed us to further confirm our earlier observations. In addition, we could infer a very weak activity of excision of $\mathrm{T}$ against 8-oxoG (data not shown). However, to further verify the substrate specificity of mycobacterial MutY, we developed an expression 
(a)

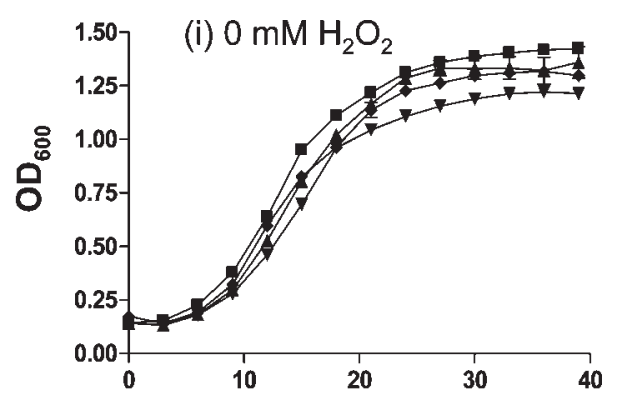

(b)

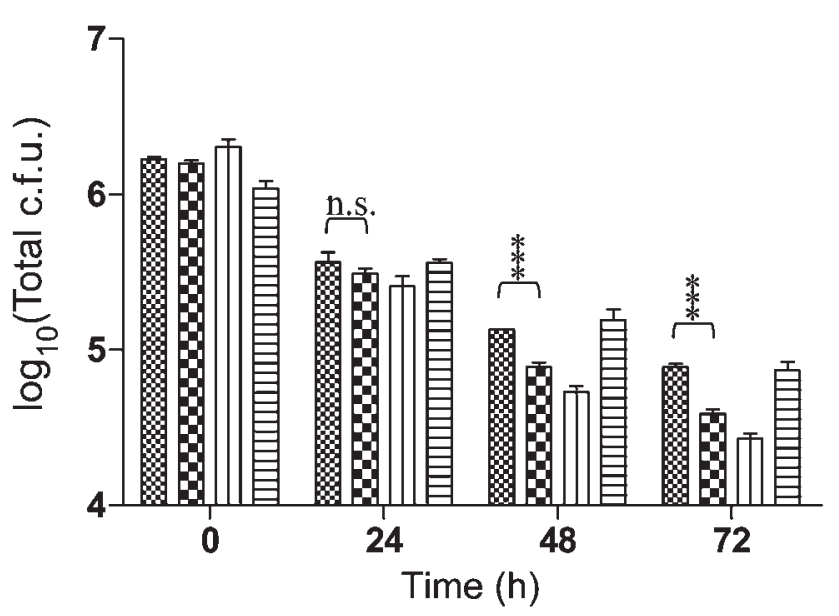

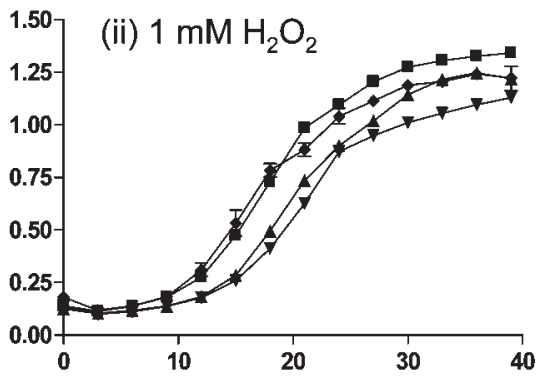

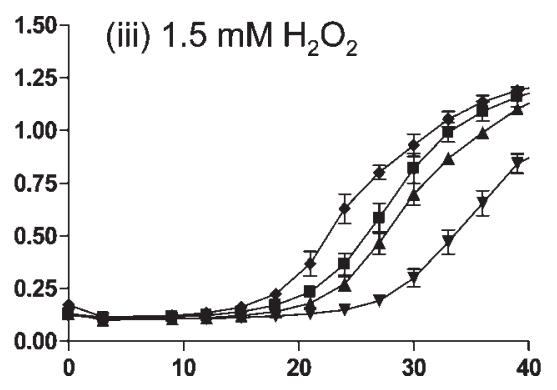

Time (h)

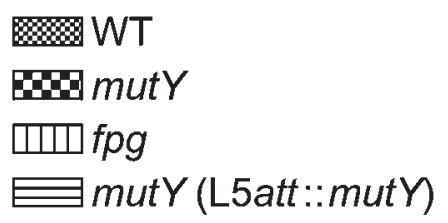

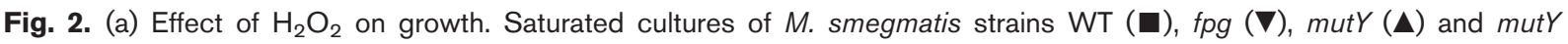
(L5att: : mutY) ( $)$ were diluted 100-fold in LBT. $\mathrm{H}_{2} \mathrm{O}_{2}$ was either not added (i) or added at $1.0 \mathrm{mM}$ (ii) and $1.5 \mathrm{mM}$ (iii) concentrations. Cultures were grown at $37{ }^{\circ} \mathrm{C}$ for $36 \mathrm{~h}$ in a Bioscreen $\mathrm{C}$ kinetic growth reader in honeycomb plates. Growth was monitored by measuring $\mathrm{OD}_{600}$. Growth curves were prepared from three independent colonies for each strain, and mean values ( $\pm \mathrm{SD}$ ) were plotted against time. (b) Survival of $M$. smegmatis strains in RAW 264.7 macrophage cells. The macrophage cells were infected with the M. smegmatis strains indicated, in triplicate. Viability of intracellular bacteria at $0,24,48$ and $72 \mathrm{~h}$ post-infection was determined by dilution plating. Counts from triplicate samples were averaged and the mean values ( \pm SD) were plotted. Student's unpaired $t$ test was used to determine the statistical significance of differences between the values ${ }^{\star \star \star}$, $P<0.0001$; n.s., not significant).

construct for M. tuberculosis MutY (MtuMutY, which shows $70 \%$ identity and $78 \%$ similarity with the $M$. smegmatis MutY). Use of the purified MtuMutY substantiated the A-excision activity of the mycobacterial MutY (Fig. 3a, compare lanes 6-8 with 5). And, consistent with the observations made from the cell-free extracts of M. smegmatis, excision of $\mathrm{G}$ and $\mathrm{T}$ (present as 8-oxoG: $\mathrm{G}$ and 8-oxoG:T pairs) was also detectable (compare lanes 2-4 with 1, and lanes 10-12 with 9, respectively). However, these activities were weak and required extended periods of incubation with the enzyme. Not unexpectedly, excision of $\mathrm{C}$ (which forms the correct base pair) from an 8-oxoG: C pair was not detectable (compare lanes 14-16 with 13).
To further our understanding of the specificity of the recognition of the base pairs containing 8-oxoG, we carried out EMSAs using native gels to resolve the complexes of MutY with various duplexes (Fig. 3b). As expected, MutY did not form stable complexes with ssDNA (compare lanes 2 and 1) or with an 8-oxoG:C pair containing dsDNA (compare lanes 10 and 9), both of which are not utilized by it as substrates, and it formed complexes with dsDNA harbouring 8-oxoG: A quite efficiently. Interestingly, MutY also efficiently complexed with dsDNA harbouring 8oxoG: $G$ or 8-oxoG:T pairs, which are utilized poorly as substrates (lanes 3-8). It is unclear whether the property of MutY complexation with the latter two DNAs represents a physiologically important phenomenon (see Discussion). 


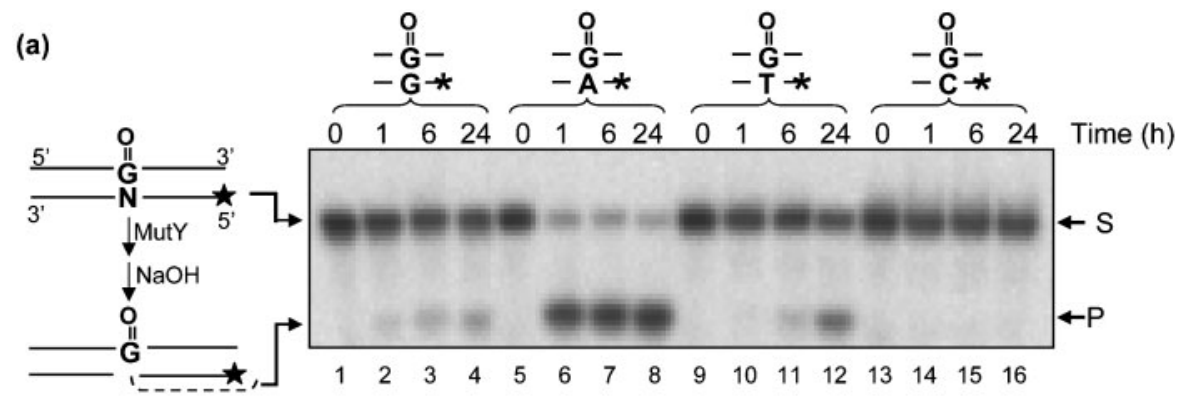

(b)

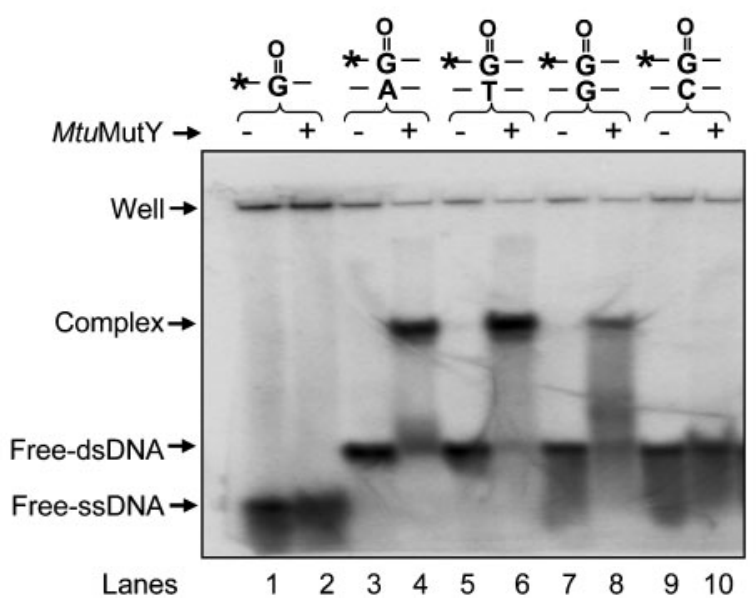

Fig. 3. (a) Time-course of the base-excision activity of MtuMutY on different oligonucleotide substrates. The duplex used in each assay is denoted at the top and the star at the end of one of the strands denotes the $5^{\prime}{ }^{32} \mathrm{P}$-end labelling. Radiolabelled substrate (50000 c.p.m.) in a $40 \mu \mathrm{l}$ reaction containing $1.25 \times$ reaction buffer was incubated at $37^{\circ} \mathrm{C}$ for 5 min. An aliquot $(8 \mu \mathrm{l})$ was taken and mixed with $2 \mu \mathrm{l} \mathrm{H}_{2} \mathrm{O}$ for use as $0 \mathrm{~h}$ time point. The reaction was then started in the remainder of the mix by adding $800 \mathrm{ng}(8 \mu \mathrm{l})$ of MtuMutY. Aliquots of $10 \mu \mathrm{l}$ were taken at 1,6 and $24 \mathrm{~h}$. All the samples including the $0 \mathrm{~h}$ time point were then treated with $\mathrm{NaOH}$ and resolved on $8 \mathrm{M}$ urea/15\% polyacrylamide gel and visualized using Biolmage Analyser. Substrate and product bands are indicated with $S$ and $\mathrm{P}$, respectively. (b) DNA oligomers (10000 c.p.m.; 0.1 pmol) as indicated were incubated with MtuMutY (200 ng) for $15 \mathrm{~min}$ on ice in EMSA buffer and resolved on the native PAGE. Bands corresponding to free ssDNA, dsDNA and complex are indicated.

\section{Error-prone incorporation of 8-oxoG into DNA}

To understand the mutation spectrum in MutY-deficient M. smegmatis, we designed substrates in which templatedependent extension of a $5^{\prime}{ }^{32} \mathrm{P}$-end labelled primer by incorporation of $G$ or 8-oxoG against any of the four standard nucleotides in the template by the DNA polymerase activities of $M$. smegmatis cell-free extracts was analysed (Fig. 4). As a control, extension of the primer in the absence of any added dNTPs was not detected (Fig. 4a, b, compare lanes 2, 6, 10 and 14 with 1, 5, 9 and 13 , respectively). As seen from the band corresponding to its extension with one nucleotide $(\mathrm{n}+1$ product), neartotal incorporation of $\mathrm{G}$ occurred against $\mathrm{C}$ in the template in the presence of either $50 \mu \mathrm{M}$ or $100 \mu \mathrm{M}$ dGTP in the reaction (Fig. 4a, compare lanes 15 and 16 with 14). Similarly, an expected incorporation of 8-oxoG occurred against $\mathrm{A}$ in the template (Fig. $4 \mathrm{~b}$, compare lanes 7 and 8 with 6). Interestingly, a weak incorporation of $G$ (as $n+1$ product) against $\mathrm{A}$ or $\mathrm{T}$ could also be detected (Fig. 4a, lanes 7 and 8; and 11 and 12, respectively). In addition, we observed a band corresponding to $\mathrm{n}+3$ product (lanes 3,4 , $7,8,11,12,15$ and 16). While the origin of this band is not clear, it could represent an error-prone incorporation of $\mathrm{G}$ by the mycobacterial DNA polymerase(s). The $n+3$ band was undetectable in the reactions not supplemented with dGTP (Fig. 4a, lanes 2, 6, 10 and 14). Importantly, under the same conditions, we observed that incorporation of 8oxoG against $\mathrm{T}$, and not unexpectedly against $\mathrm{C}$, in the template occurred somewhat more significantly (Fig. 4b, lanes 11,12, 15 and 16). Such an incorporation of 8-oxoG was further highlighted by the presence of $n+2$ and $n+3$ bands of gradually decreasing intensities (Fig. 4b, lanes 11, 12, 15 and 16). Although a better understanding of the erroneous incorporation of nucleotides in DNA in mycobacteria will have to await detailed studies on purification and biochemical analyses of the various DNA polymerases, the experiments in Fig. 4 using cell-free 


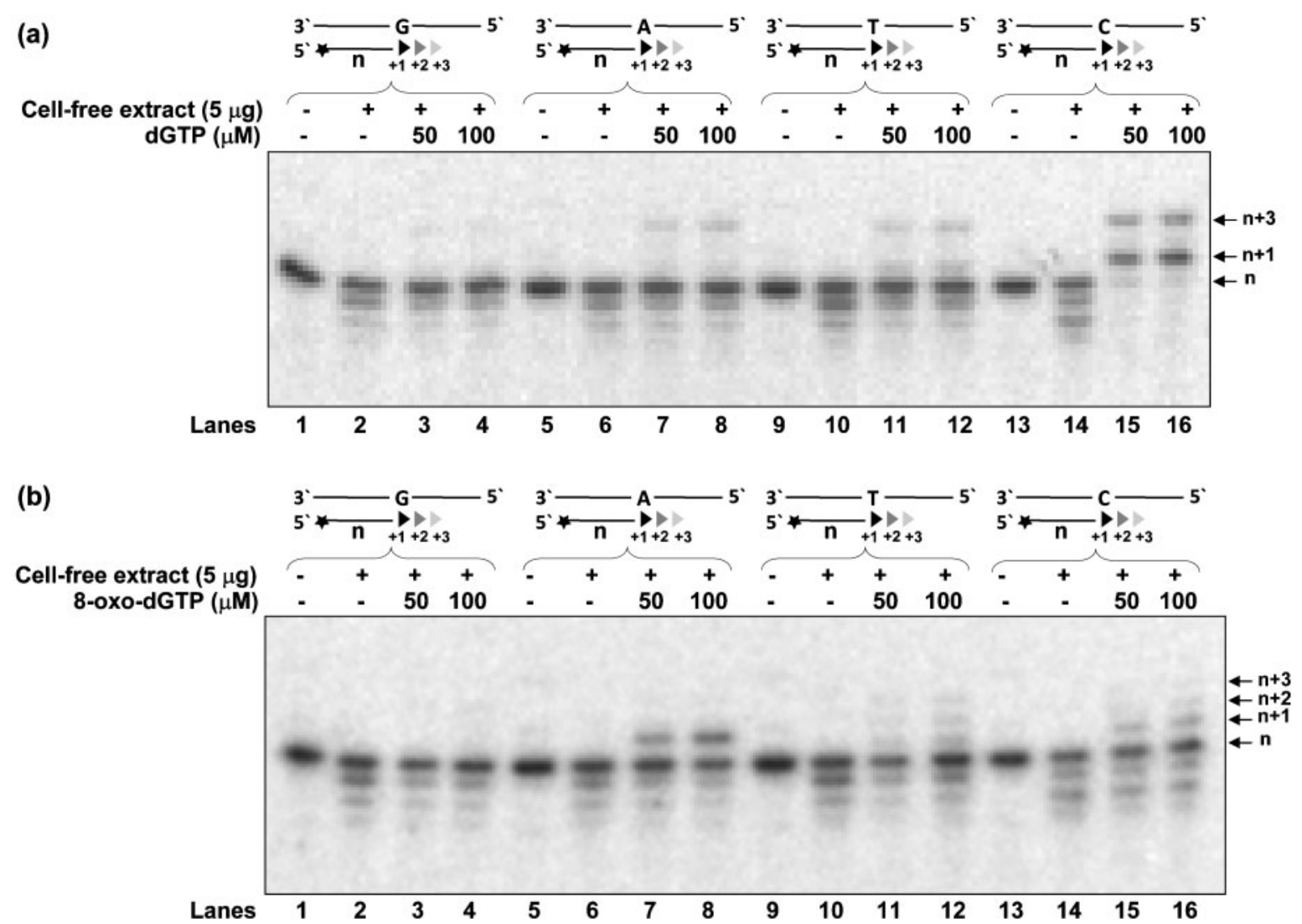

Fig. 4. Primer extension assays in cell-free extracts of $M$. smegmatis. The duplex DNA substrates containing $5^{\prime}$ overhanging sequence in the template (as shown above the lanes) were prepared by annealing Comp-G (lanes 1-4), Comp-A (lanes 5-8), Comp-T (lanes 9-12) and Comp-C (lanes 13-16) oligomers with the $5^{\prime}{ }^{32} \mathrm{P}$-end labelled primer (Extension-oligo). The assays using $5 \mu \mathrm{g}$ cell-free extract (indicated with ' + ') were carried out in the absence (lanes 2, 6, 10 and 14), and in the presence of $50 \mu \mathrm{M}$ (lanes 3, 7, 11 and 15) or $100 \mu \mathrm{M}$ (lanes 4, 8, 12 and 16) of added dGTP (a) or 8-oxo-dGTP (b), at $37{ }^{\circ} \mathrm{C}$ for 3 min, analysed on $8 \mathrm{M}$ urea/15\% polyacrylamide gel and visualized on Biolmage Analyser. Lanes 1, 5, 9 and 13 are no cell-free extract and no dNTP, substrate alone controls. The primer size $(n)$ and the extension products $(n+1, n+2$ and $n+3)$ are as indicated with the arrows on the right hand side margins.

extracts do provide us with a strong first indication of the possibility of incorporation of 8-oxoG into DNA not only against $\mathrm{A}$ and $\mathrm{C}$ but also against $\mathrm{T}$ (Fig. $4 \mathrm{~b}$ ).

\section{DISCUSSION}

The redox potentials of $\mathrm{G}, \mathrm{A}, \mathrm{C}$ and $\mathrm{T}$ are 1.3, 1.4, 1.6 and $1.7 \mathrm{~V}$, respectively. Guanine, with the lowest redox potential, is thus chemically the most susceptible base in DNA to oxidative stress, resulting in the formation of 8oxoG (Steenken \& Jovanovic, 1997). The G $+\mathrm{C}$ richness of the genome of mycobacteria and the habitat of the pathogenic species in macrophages, where they are exposed to reactive oxygen species, suggests that their DNA is naturally at a high risk of incurring oxidative damage. The base-excision repair enzymes Fpg (MutM) and MutY are crucial guardians of bacterial genomes against such oxidative damage. We have previously analysed the effects of Fpg deficiency in M. smegmatis (Jain et al., 2007). Here, we have investigated the effects of MutY deficiency on various properties of this bacterium.

We noticed that unlike Fpg deficiency, MutY deficiency did not result in a detectable phenotype in response to treatment with $\mathrm{H}_{2} \mathrm{O}_{2}$. And although the MutY deficiency resulted in a decrease in the survival of the mut $Y$ strain in a mouse macrophage cell line, the impact was minor (Fig. 2b). Also, unlike the earlier studies in E. coli (Michaels et al., 1992) or P. aeruginosa (Sanders et al., 2009), loss of MutY in M. smegmatis did not significantly affect the mutation rate (Table 2). It may be mentioned that mycobacteria possess a number of MutM activities (Sidorenko et al., 2008). It has also been shown before that increased levels of MutM activity compensate for the deficiency of MutY (Michaels et al., 1992). This could be a reason for the smaller impact of MutY deficiency in mycobacteria. However, investigation of the mutation 
spectrum in the RRDR of the $r p o B$ locus did show a significant increase in $\mathrm{C}$ to $\mathrm{A}$ (or $\mathrm{G}$ to $\mathrm{T}$ ) mutations, which otherwise occur at an extremely low frequency in mycobacteria (Boshoff et al., 2003; Jain et al., 2007). The MutY deficiency also resulted in a considerable increase in A to $C$ ( $T$ to $G$ ) and a smaller increase in A to $G$ (T to $C$ ) mutations (Table 3).

The biochemical activity assays reveal that similar to the $E$. coli MutY, the mycobacterial MutY excised A from the 8oxoG: A pair. Excisions of $\mathrm{G}$ or $\mathrm{T}$ from their respective pairs with 8-oxoG also occurred, but these activities were poor (Fig. 3a). We have earlier shown that mycobacterial DNA polymerase(s) result in incorporation of $A$ (in addition to $\mathrm{G}$ and $\mathrm{C}$ ) against 8-oxoG (Jain et al., 2007). Hence, a detectable increase in $\mathrm{C}$ to $\mathrm{A}$ mutations upon MutY deficiency in mycobacteria is readily understood due to its conventional role as adenosine DNA glycosylase in the GO repair pathway. However, an atypical increase in A to $\mathrm{C}$ (or $\mathrm{T}$ to $\mathrm{G}$ ) and to some extent $\mathrm{A}$ to $\mathrm{G}$ (or $\mathrm{T}$ to $\mathrm{C}$ ) mutations requires an explanation.

Fig. 5 summarizes the major steps in the GO repair pathway as established in E. coli (Michaels \& Miller, 1992) except that based on our earlier study (Jain et al., 2007), misincorporation of $\mathrm{G}$ (in addition to $\mathrm{A}$ ) has also been included if the replication of 8-oxoG containing template occurred prior to its excision by Fpg (steps 4 and 6, right). Steps 1 to 9 in this pathway are either involved in excision repair of 8-oxoG to maintain the integrity of the genome (step 3) or lead to mutations (step 9). Absence of an increase in $\mathrm{C}$ to $\mathrm{G}$ mutations as a consequence of MutY deficiency, and a relatively low (15\%) occurrence of C to A mutations, suggests that much of the repair of the 8-oxoG arising in DNA by its oxidative damage occurs by Fpg prior to replication (step 2).

However, the presence of 8-oxoG in DNA may also arise from an alternative route of direct incorporation of 8-oxodGTP from the cellular pool (which may accumulate because of the oxidative damage of dGTP, step 10) during replication by an error-prone DNA polymerase (step 12). Although the levels of 8-oxo-dGTP are kept to a minimum by the enzymic activity of MutT, which hydrolyses 8-oxodGTP to 8-oxo-dGMP and $\mathrm{PP}_{\mathrm{i}}$ (step 11), incorporation of the residual 8-oxo-dGTP (e.g. against A and T) in DNA could occur (Fig. 4b) by error-prone DNA polymerases

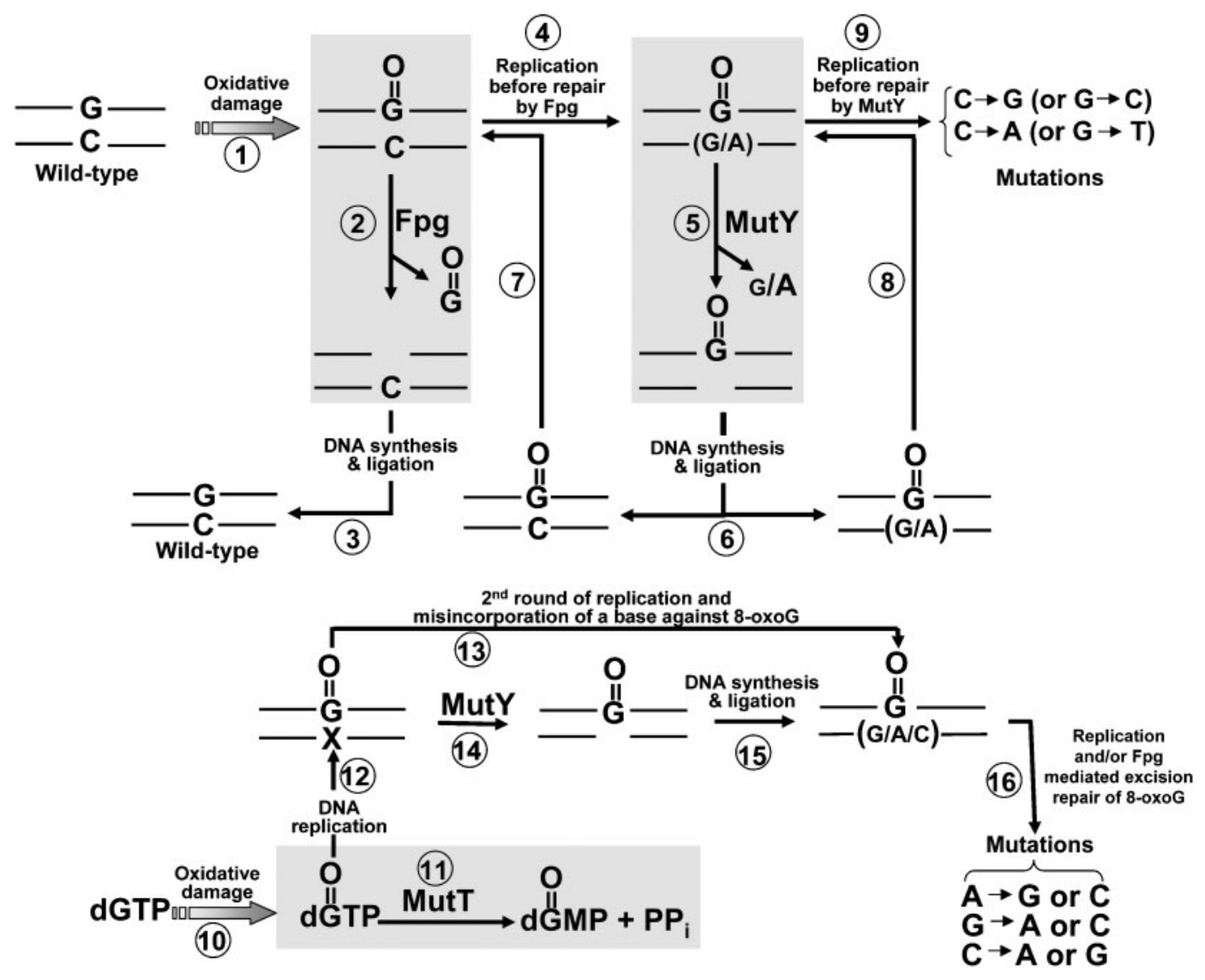

Fig. 5. GO repair pathway in mycobacteria, highlighting the incorporation of $\mathrm{G}$ against 8-oxoG (steps 4 and 6 , right). Also shown is a scheme for generation of mutations following misincorporation of 8-oxoG during replication (steps 12-16). For details of various steps refer to the Discussion. 
(Davis \& Forse, 2009; Shimizu et al., 2003). Paradoxically, MutY activity on these base pairs (step 14) would lead to excision of the correct base from DNA with severe consequences of misincorporations during gap filling, and fixation of a mutation through steps 14-16. Additionally, the mycobacterial Fpg-mediated excision of the 8-oxoG (step 16, Jain et al., 2007) may also contribute to the fixation of the mutations. In fact, occurrence of such a phenomenon would explain the high background (34\%, Table 3) of A to $\mathrm{G}$ (or T to $\mathrm{C}$ ) mutations. And, while in steps $14-16$, the process is shown to be facilitated by MutY, such a fixation of mutations could occur even in the absence of MutY by direct replication (step 13). As is evident from the data in Table 3, the absence of MutY would lead to preferential processing of DNA (with misincorporated 8-oxoG) via step 13 and result in even more mutations. How MutY lowers mutation fixation by acting at step 14 remains unclear. However, it may well be that complexation of MutY with DNA containing mispaired 8-oxoG (Fig. 3b) somehow facilitates 8-oxoG excision by Fpg (Jain et al., 2007) or other uncharacterized Fpg-like proteins found in mycobacteria. Such a proposal is supported by our earlier observation that Fpg deficiency also resulted in an increase in $A$ to $G$ ( $T$ to $\mathrm{C}$ ) mutations.

Thus, a high-level occurrence of 8-oxo-dGTP in the cellular pool for the $\mathrm{G}+\mathrm{C}$-rich mycobacteria could have severe consequences. Genome sequence analysis reports the presence of four probable MutT proteins in M. tuberculosis and another five Nudix-box-containing proteins to which MutT belongs. However, unlike the E. coli counterpart (Maki \& Sekiguchi, 1992), none of the four MutTs shows a high specificity towards 8-oxo-dGTP (Dos Vultos et al., 2006). It has also been reported (Moreland et al., 2009) that the MutT2 of M. tuberculosis, which is the most similar to E. coli MutT, is actually a dCTPase. In fact, in M. smegmatis the orthologue of M. tuberculosis MutT2 is annotated as a dCTPase. However, at present, it cannot be ruled out that one or more of the remaining MutTs could actually possess 8-oxo-dGTPase activity. Nevertheless, the occurrence of A to $G$ mutations in the wild-type and an increase in A to $G$ and $\mathrm{A}$ to $\mathrm{C}$ mutations indicates that the steady-state levels of 8-oxo-dGTP may be high in mycobaceria. Clearly, understanding of the distinctive features of the DNA repair pathways in mycobacteria will be an exciting area of research to unravel the mechanisms that lead to development of multiple drug resistance as well as to design novel strategies to control the growth of this important class of pathogenic bacteria.

\section{ACKNOWLEDGEMENTS}

We thank our laboratory colleagues for their suggestions on the manuscript. This work received financial support from the Department of Biotechnology, New Delhi (DBT). K. K. and P. K. were supported by senior research fellowships of the Council of Scientific and Industrial Research, New Delhi. T. S. is a Department of Science and Technology, New Delhi, supported young investigator. R. J. was supported by a post-doctoral fellowship of DBT.

\section{REFERENCES}

Au, K. G., Clark, S., Miller, J. H. \& Modrich, P. (1989). Escherichia coli mut $Y$ gene encodes an adenine glycosylase active on G/A mispairs. Proc Natl Acad Sci U S A 86, 8877-8881.

Boshoff, H. I., Reed, M. B., Barry, C. E., III \& Mizrahi, V. (2003). DnaE2 polymerase contributes to in vivo survival and the emergence of drug resistance in Mycobacterium tuberculosis. Cell 113, 183-193.

Bruner, S. D., Norman, D. P. G., Fromme, J. C. \& Verdine, G. L. (2000). Structural and mechanistic studies on repair of 8-oxoguanine in mammalian cells. Cold Spring Harb Symp Quant Biol 65, 103-111.

Cole, S. T., Brosch, R., Parkhill, J., Garnier, T., Churcher, C., Harris, D., Gordon, S. V., Eiglmeier, K., Gas, S. \& other authors (1998). Deciphering the biology of Mycobacterium tuberculosis from the complete genome sequence. Nature 393, 537-544.

David, H. L. (1970). Probability distribution of drug-resistant mutants in unselected populations of Mycobacterium tuberculosis. Appl Microbiol 20, 810-814.

David, S. S., O'Shea, L. O. \& Kundu, S. (2007). Base excision repair of oxidative DNA damage. Nature 447, 941-950.

Davis, E. O. \& Forse, L. N. (2009). DNA repair: key to survival? In Mycobacterium: Genomics and Molecular Biology, pp. 79-119. Edited by T. Parish \& A. Brown. London: Caister Academic Press.

Delaney, S., Neeley, W. L., Delaney, J. C. \& Essigmann, J. M. (2007). The substrate specificity of MutY for hyperoxidized guanine lesions in vivo. Biochemistry 46, 1448-1455.

Dheenadhayalan, V., Delogu, G. \& Brennan, M. J. (2006). Expression of the PE_PGRS 33 protein in Mycobacterium smegmatis triggers necrosis in macrophages and enhanced mycobacterial survival. Microbes Infect 8, 262-272.

Dos Vultos, T., Blazquez, J., Rauzier, J., Matic, I. \& Gicquel, B. (2006). Identification of nudix hydrolase family members with an antimutator role in Mycobacterium tuberculosis and Mycobacterium smegmatis. J Bacteriol 188, 3159-3161.

Farr, S. B. \& Kogoma, T. (1991). Oxidative stress response in Escherichia coli and Salmonella typhimurium. Microbiol Rev 55, 561585.

Fowler, R. G., White, S. J., Koyama, C., Moore, S. C., Dunn, R. L. \& Schaaper, R. M. (2003). Interactions among the Escherichia coli mutT, mutM and $m u t Y$ damage prevention pathways. DNA Repair (Amst) 2, 159-173.

Fraga, C. G., Shigenaga, M. K., Park, J.-W., Degan, P. \& Ames, B. N. (1990). Oxidative damage to DNA during aging: 8-hydroxy-2' deoxyguanosine in rat organ DNA and urine. Proc Natl Acad Sci U S A 87, 4533-4537.

Jain, R., Kumar, P. \& Varshney, U. (2007). A distinct role of formamidopyrimidine DNA glycosylase (MutM) in down-regulation of accumulation of $\mathrm{G}, \mathrm{C}$ mutations and protection against oxidative stress in mycobacteria. DNA Repair (Amst) 6, 1774-1785.

Kurthkoti, K., Kumar, P., Jain, R. \& Varshney, U. (2008). Important role of the nucleotide excision repair pathway in Mycobacterium smegmatis in conferring protection against commonly encountered DNA-damaging agents. Microbiology 154, 2776-2785.

Lagier, B., Pelicic, V., Lecossier, D., Prod'hom, G., Rauzier, J., Guilhot, C., Gicquel, B. \& Hance, A. J. (1998). Identification of genetic loci implicated in the survival of Mycobacterium smegmatis in human mononuclear phagocytes. Mol Microbiol 29, 465-475.

Lu, A. L. \& Chang, D. Y. (1988). Repair of single base pair transversion mismatches of Escherichia coli in vitro: correction of certain $\mathrm{A} / \mathrm{G}$ mismatch is independent of dam methylation and host mutHLS gene function. Genetics 118, 593-600. 
Maki, H. \& Sekiguchi, M. (1992). MutT protein specifically hydrolyses a potent mutagenic substrate for DNA synthesis. Nature 355, 273275.

Michaels, M. L. \& Miller, J. H. (1992). The GO system protects organisms from the mutagenic effect of the spontaneous lesion 8hydroxyguanine (7,8-dihydro-8-oxoguanine). J Bacteriol 174, 63216325.

Michaels, M. L., Cruz, C., Grollmant, A. P. \& Miller, J. H. (1992). Evidence that MutY and MutM combine to prevent mutations by an oxidatively damaged form of guanine in DNA. Proc Natl Acad Sci U S A 89, 7022-7025.

Mizrahi, V. S. \& Andersen, S. J. (1998). DNA repair in Mycobacterium tuberculosis. What have we learnt from the genome sequence? Mol Microbiol 29, 1331-1339.

Mo, J.-Y., Maki, H. \& Sekiguchi, M. (1992). Hydrolytic elimination of a mutagenic nucleotide, 8-oxodGTP, by human 18-kilodalton protein: sanitization of nucleotide pool. Proc Natl Acad Sci U S A 89, 11021-11025.

Moreland, N. J., Charlier, C., Dingley, A. J., Baker, E. N. \& Lott, J. S. (2009). Making sense of a missense mutation: characterization of MutT2, a Nudix hydrolase from Mycobacterium tuberculosis, and the G58R mutant encoded in W-Beijing strains of $M$. tuberculosis. Biochemistry 48, 699-708.

Pelicic, V., Jackson, M., Reyrat, J. M., Jacobs, W. R., Jr, Gicquel, B. \& Guilhot, C. (1997). Efficient allelic exchange and transposon mutagenesis in Mycobacterium tuberculosis. Proc Natl Acad Sci U S A 94, 10955-10960.

Sanders, L. H., Sudhakaran, J. \& Sutton, M. D. (2009). The GO repair system prevents ROS-induced mutagenesis and killing in Psuedomonas aeruginosa. FEMS Microbiol Lett 294, 89-96.

Schlosser-Silverman, E., Elgrably-Weiss, M., Rosenshine, I., Kohen, R. \& Altuvia, S. (2000). Characterization of Escherichia coli DNA lesions generated within J774 macrophages. J Bacteriol 182, 5225-5230.
Shimizu, M., Gruz, P., Kamiya, H., Kim, S. R., Pisani, F. M., Masutani, C., Kanke, Y., Harashima, H., Hanaoka, F. \& Nohmi, T. (2003). Erroneous incorporation of oxidized DNA precursors by Y-family DNA polymerases. EMBO Rep 4, 269-273.

Sidorenko, V. S., Rot, M. A., Filipenko, M. L., Nevinsky, G. A. \& Zharkov, D. O. (2008). Novel DNA glycosylases from Mycobacterium tuberculosis. Biochemistry (Mosc) 73, 442-450.

Snapper, S. B., Melton, R. E., Mustafa, S., Kieser, T. \& Jacobs, W. R., Jr (1990). Isolation and characterization of efficient plasmid transformation mutants of Mycobacterium smegmatis. Mol Microbiol 4, 1911-1919.

Srinath, T., Bharti, S. K. \& Varshney, U. (2007). Substrate specificities and functional characterization of a thermo-tolerant uracil DNA glycosylase (UdgB) from Mycobacterium tuberculosis. DNA Repair (Amst) 6, 1517-1528.

Steenken, S. \& Jovanovic, S. V. (1997). How easily oxidizable is DNA? One-electron reduction potentials of adenosine and guanosine radicals in aqueous solution. J Am Chem Soc 119, 617-618.

Tajiri, T., Maki, H. \& Sekiguchi, M. (1995). Functional cooperation of MutT, MutM and MutY proteins in preventing mutations caused by spontaneous oxidation of guanine nucleotide in Escherichia coli. Mutat Res 336, 257-267.

Tsai-Wu, J. J., Liu, H. F. \& Lu, A. L. (1992). Escherichia coli MutY protein has both $\mathrm{N}$-glycosylase and apurinic/apyrimidinic endonuclease activities on A.C and A.G mispairs. Proc Natl Acad Sci U S A 89, 8779-8783.

Venkatesh, J., Kumar, P., Krishna, P. S., Manjunath, R. \& Varshney, U. (2003). Importance of uracil DNA glycosylase in Pseudomonas aeruginosa and Mycobacterium smegmatis, $\mathrm{G}+\mathrm{C}$-rich bacteria, in mutation prevention, tolerance to acidified nitrite, and endurance in mouse macrophages. J Biol Chem 278, 24350-24358.

Edited by: S. V. Gordon 